Check for updates

Cite this: J. Mater. Chem. B, 2019, 7, 3310

\title{
A rugged, self-sterilizing antimicrobial copper coating on ultra-high molecular weight polyethylene: a preliminary study on the feasibility of an antimicrobial prosthetic joint material $\dagger$
}

\author{
Ke Wu, (D) ab Samuel P. Douglas, ${ }^{a}$ Gaowei Wu, (D) ${ }^{c}$ Alexander J. MacRobert, ${ }^{d}$ \\ Elaine Allan, ${ }^{\text {b }}$ Caroline E. Knapp ${ }^{a}$ and Ivan P. Parkin (D)*a
}

\begin{abstract}
We report here for the first time how the combination of a precursor solution and low temperature $\left(170{ }^{\circ} \mathrm{C}\right)$ aerosol assisted chemical vapour deposition were used to bond a copper coating to ultra-high molecular weight polyethylene (UHMWPE) and promote robustness. This metallic thin film remained intact on the UHMWPE substrate after the Scotch tape test and showed notable wear-resistance after 10 cycles of sand paper-abrasion. Antimicrobial assays against both Escherichia coli and Staphylococcus aureus revealed potent dark bactericidal activity with $99.999 \%$ reduction in bacterial number within 15 minutes. These results suggest that the modified UHMWPE could be a potential candidate for antimicrobial plastics and in the long term may find application in prosthetic joint applications.
\end{abstract}

Received 4th March 2019

Accepted 23rd April 2019

DOI: 10.1039/c9tb00440h

rsc.li/materials-b

\section{Introduction}

The extraordinary physical and mechanical properties of UHMWPE enable it to be widely used in textiles, conveying and food processing machinery parts. Its combination of abrasion resistance and low wear have also enabled it to be used as components for hip and knee implants worldwide. For example, joint replacements in the UK are in high demand with 2526601 operations recorded in the National Joint Registry between 2003 to $2017 .{ }^{1}$ In total joint replacement surgery, polyethylene plays an essential role in manufacturing prosthetic joint materials. Metalon-polyethylene bearing type joints account for the largest usage among all type of replacement followed by ceramic-on polyethylene. ${ }^{1}$ In total knee replacement (TKR), the tibia component is usually comprised of a metal alloy tray combined with a polyethylene insert. Lately, it is more common to see integrated polyethylene tibia components in use in TKR. The widespread application of prosthetic joints offers patients the opportunity to restore their mobility and alleviate pain.

\footnotetext{
${ }^{a}$ Department of Chemistry, University College London, 20 Gordon Street, London, WC1E 0AJ, UK. E-mail: i.p.parkin@ucl.ac.uk; Tel: +44 (0)207679 2818

${ }^{b}$ Division of Microbial Diseases, UCL Eastman Dental Institute,

University College London, 256 Gray's Inn Road, London WC1X 8LD, UK

${ }^{c}$ Department of Chemical Engineering, University College London, Torrington Place, WC1E JJE, UK

${ }^{d}$ Division of Surgery \& Interventional Science, Charles Bell House, 43-45 Foley St, London, W1W 7TS, UK

$\dagger$ Electronic supplementary information (ESI) available. See DOI: 10.1039/ c9tb00440h
}

However joint replacement can result in failure with prosthetic joint infection (PJI) being one of the most torturous complications with fierce joint pain even though the morbidity is approximately $1-2 \% .^{2}$ The total number of young patients undergoing joint replacement surgeries has increased dramatically in the last decade. ${ }^{1}$ In both hip and knee replacement cases, the revision rate for all patients under 55, over 13 years after insertion can be as high as $13.5 \% .^{3}$

The incidence of PJI can arise between 3 to 24 months after implantation and can be triggered intraoperatively. ${ }^{4}$ The causative pathogens for early infection are typically Grampositive cocci, such as Staphylococcus aureus (S. aureus) and Gram-negative bacilli like Escherichia coli (E. coli), whereas late-onset PJI can be started by less virulent organisms ${ }^{4,5}$ dependant on the patient's circumstances. PJI can be treated by means of medical and/or surgical approaches with or without prosthetic retention, but in the more severe cases, resection and amputation may be necessary. ${ }^{4,6,7}$

Treatment of patients with acute infection but with a relatively stable implant usually requires preliminary work such as debridement, antibiotic therapy and implant retention (DAIR). ${ }^{5}$ An intervention of single or two-stage surgical revision might be prioritised if the DAIR procedure failed. It is worth noting that traumatic arthrotomy is unavoidable for all the procedures mentioned above. This will inevitably exert both psychological and physical suffering to the patients especially for the elderly.

Successful PJI resolution requires the use of antimicrobial treatment in the majority of surgical procedures. ${ }^{2}$ Antibiotics can 
be delivered to the infected tissues by intravenous systemic administration. ${ }^{2,4-6}$ But effective drug infiltration might be restricted by insufficient blood flow in the area concerned. ${ }^{6}$ Providing high concentration of antibiotics over a local area seems to resolve this issue. Antibiotic impregnated polymethylmethacrylate (PMMA) bone cement is commonly applied in an arthroplasty exchange procedure to provide local antimicrobial therapy to the infected tissue. ${ }^{5,6}$ Suhardi et al. emphasised the necessity of high concentrations of antibiotics in PMMA bone cement in order to maintain efficient drug diffusion due to the peculiar spherical drug morphology. ${ }^{6}$ However, high drug load can lead to a toxic serum concentration. ${ }^{2}$ Moreover, the comparatively weak mechanical strength of these units might cause load-bearing failure. ${ }^{6}$ Both antibiotic impregnated beads and a collagen sponge can be used to inhibit bacterial growth locally. The antibiotic beads are a foreign body and need to be removed through surgical procedures; a further trauma for patients. ${ }^{2,8}$ Even though the soluble antibiotic-loaded collagen sponge can address the shortcoming of an additional surgical step, one disadvantage of such material is that it can cause excess wound secretion. ${ }^{9}$ A major concern with the use of antibiotics is the development of bacterial resistance even though the dosage is significantly beyond the minimum inhibitory concentration. $^{4}$

Copper metal is well known as an antimicrobial. Research by Sehmi et al. showed that copper nanoparticles are promising candidates for use in catheter materials to potentially reduce the incidence of hospital acquired infections. ${ }^{10}$ Antimicrobial copper coatings on orthopaedic material like titanium and titanium alloy have also been reported by Wan et al. ${ }^{11}$ The alternative cycle of cupric and cuprous ions trigger an intracellular redox potential which can lead to instability and therefore cell damage. ${ }^{12}$ In addition, 'Fenton type' chemistry in the presence of molecular oxygen following the production of superoxide and other reactive oxygen species can cause detrimental cellular damage to the bacteria. ${ }^{12,13}$ Bacterial cell wall synthesis is carried out by enzymes known as DD-transpeptidases which are the target of $\beta$-lactams antibiotics such as penicillin. Some bacteria produce an alternative enzyme known as LD-transpeptidase which allows cell wall synthesis even in the presence of $\beta$-lactams and a recent study showed that copper ions can inhibit LD-transpeptidases thus rendering $\beta$-lactamresistant bacteria susceptible. ${ }^{12}$

The intrinsically inert UHMWPE provides stable long-term performance in prosthetic applications, but this also means that the incorporation of antimicrobial agents is difficult. Following previous work on low temperature precursor conversion, ${ }^{14,15}$ the key idea here was to introduce a selfreducing copper precursor, that can undergo pyrolysis at relatively low temperature to form copper containing particles onto a temperature sensitive polymer. This precursor has a relatively low level of organic content and was shown to yield moderately pure copper metal particles. Hydrogen gas formed as a by-product in this self-reduction reaction can inhibit the further oxidation of the pure copper thin film. A few studies have been conducted to incorporate $\mathrm{Cu}$ into UHMWPE. Ion implantation is one of the techniques however high implantation energy may cause damage to the polymeric chain of the UHMWPE. ${ }^{16}$ Others have made $\mathrm{Cu}$-UHMWPE composite. ${ }^{17}$ Copper coating on surfaces results in a high concentration of antimicrobial agent which is present locally to induce contact killing of bacteria with little risk of resistance development.

$\mathrm{Cu}$ is relatively non-toxic to mammals. ${ }^{18}$ Many studies have shown that copper containing materials demonstrates good biocompatibility. ${ }^{17,19-21}$ A good example is the well-accepted application of the copper intrauterine device (IUD) for contraception. This device can remain in place for as long as 10 years. $^{22}$

The aim of this study was to synthesis a Cu coating deposited on the UHMWPE and to characterise the coating in terms of composition, mechanical properties, morphology, leaching and antimicrobial activity. The rationale was to deposit a surface coating of copper particles on top of UHMWPE via AACVD which is a commonly used prosthetic joint material. Light-independent antimicrobial activity exhibited by $\mathrm{Cu}$ is a crucial feature for low light environments. In this study, we show that minor amounts of copper oxide had formed along with the pure copper coating. The copper-coated UHMWPE was tested against representative Gram-positive and Gram-negative bacterial species. Antimicrobial tests incorporating bovine serum albumin (BSA) were included to investigate the effect of organic fouling on the antimicrobial activity of the Cu-coated UHMWPE. $0.03 \%$ BSA was used to mimic relatively clean condition and $0.3 \%$ BSA represented dirty condition. ${ }^{23}$ The presence of proteinaceous components in the antimicrobial tests provided a more accurate representation of actual in situ conditions.

\section{Experimental}

\section{Material}

1-Amino-2-propanol and ultra-high molecular weight polyethylene, methanol and Bovine Serum Albumin (BSA) were purchased from Sigma Aldrich. Copper formate tetrahydrate was purchase from Alfa Aesar and used without further purification.

\section{Manufacture of UHMWPE substrate}

Ultra-high molecular weight polyethylene powder was poured into a mould that was comprised of a rectangular stainless-steel window (inner size: $56.5 \times 50.0 \mathrm{~mm}$, outer size: $81.3 \times 74.5 \mathrm{~mm}$ ) two Melinex thin sheets and two stainless steel plates to form a 'sandwich'. The 'sandwich' (Fig. 1(a)) was placed in the compression moulding machine (SEBA Developments, Type VP 6G) to allow the UHMWPE powder to melt for $1 \mathrm{~min}$. The powder was consolidated by operating the machine at $200{ }^{\circ} \mathrm{C}$ and $450 \mathrm{MPa}$ for $1 \mathrm{~min}$. The mould was then cooled down to room temperature, the result was an UHMWPE thin sheet with an average thickness of $2.34 \mathrm{~mm}$ measured by Hilka Venier Caliper.

\section{Copper precursor preparation}

1-Amino-2-propanol (2.75 g, $35.4 \mathrm{mmol})$ was mixed with copper(II) formate tetrahydrate $(4.00 \mathrm{~g}, 17.7 \mathrm{mmol})$ to generate 
(a)



(b)

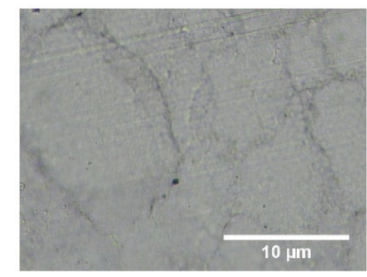

Fig. 1 (a) A sandwich structure of the procedure undergoes compression moulding; (b) an example of compression moulded UHMWPE imaged using a light microscope (GX microscope, GXML 3230).

a viscous royal blue solution, the reaction is exothermic and produces water vapour. The mixture was continuously stirred for a further 10 minutes until the vapour had dispersed. Methanol $(60 \mathrm{~mL})$ was added to the slurry to yield a bright blue precursor solution. The reaction was sealed and stirred overnight.

\section{Deposition of copper film on UHMWPE via AACVD}

Each UHMWPE square $(1 \times 1 \mathrm{~cm})$ was cleaned by detergent, acetone and propan-2-ol for later use as a substrate. During the deposition, $30 \mathrm{~mL}$ of copper precursor in the glass bubbler was atomised to form an aerosol mist using a nebulizer. A stream of $\mathrm{N}_{2}$ gas with flow rate $0.3 \mathrm{~L} \mathrm{~min}^{-1}$ passed through the bubbler and travelled all the way towards the reaction chamber with substrates on top of the heating block, then eventually reach the exhaust. Where necessary a joint of each part was connected by polytetrafluorethylene (PTFE) tube to ensure a smooth flow of the carrier gas. A thin stainless-steel plate was fitted above the substrate to form a laminar flow over the chamber. A schematic diagram of the AACVD reactor is shown in Fig. S1 (ESI $\dagger$ ). The deposition temperature was maintained at $170{ }^{\circ} \mathrm{C}$ throughout the whole process for about $90 \mathrm{~min}$. At the end of the deposition, $\mathrm{N}_{2}$ gas was allowed to flow until the quartz tube reached room temperature.

\section{Material analysis}

X-ray photoelectron spectroscopy (XPS). The chemical composition of the copper thin film UHMWPE sample was analysed by Thermo Scientific K-alpha photoelectron spectrometer using monochromatic $\mathrm{Al}-\mathrm{K}_{\alpha}$ radiation. High resolution scans of $\mathrm{Cu}(2 \mathrm{p}), \mathrm{O}(1 \mathrm{~s})$ and $\mathrm{C}(1 \mathrm{~s})$ were obtained. Peak positions were calibrated against C $1 \mathrm{~s}(285 \mathrm{eV})$ and subsequently fitted by CasaXPS software.

Scanning electronic microscope (SEM). Surface structure and material thickness were obtained by using a JEOL JSM-6301F SEM at an accelerating voltage of $10 \mathrm{kV}$.

X-ray diffraction (XRD). The crystal phase of each sample was obtained by Bruker D8 X-ray diffractometer emitting monochromatic $\mathrm{Cu} \mathrm{K} \alpha 1(\lambda=1.54056 \AA)$ and $\mathrm{K} \alpha 2(\lambda=1.54439 \AA)$ radiation under $40 \mathrm{kV}$ voltage and $40 \mathrm{~mA}$ current power supply. The operation range of diffraction angle was between 10 to $66^{\circ}$.

Differential scanning calorimeter (DSC). DSC was obtained by using a Netzsch STA 449 C Jupiter Thermo-microbalance in an open aluminum sample pan. All analysis was carried out by using Netzsch Preteus Analysis software. The theoretical heats of fusion of $100 \%$ crystalline UHMWPE, $\Delta H_{\mathrm{f}}=289.3 \mathrm{~J} \mathrm{~g}^{-1}$ has been used throughout the analysis.

\section{Mechanical test}

The compression moulded UHMWPE was heated to $170{ }^{\circ} \mathrm{C}$ for 90 min in the AACVD reactor in a $\mathrm{N}_{2}$ gas environment and cooled down to room temperature. This sample refers to remelted UHMWPE. Type IV specimen dimension was adapted for both of the untreated and remelted UHMWPE samples $\left(n=5\right.$ each) in accordance with ASTM D638 $-14,{ }^{24}$ all samples were cut by laser cutter (Trotec Speedy 100R). Tensile testing was performed by using an Instron 5565 at a speed of $100 \mathrm{~mm} \mathrm{~min}^{-1}$. The yield strength, ultimate tensile strength and young's modulus were calculated.

\section{Water contact angle measurement}

A FTA 1000 Drop Shape Instrument was employed to measure the equilibrium water $(5.0 \mu \mathrm{L})$ contact angle for each sample type. The average contact angle was measured over 3 measurements for each type of sample, using a droplet of water dispensed by gravity from a gauge 30 needle attached to a camera. The data was subsequently analysed using FTA32 software.

\section{Functional test}

A Scotch ${ }^{\mathrm{TM}}$ tape adhesive test was carried out to investigate the performance of $\mathrm{Cu}$ coating adhesion on UHMWPE substrate. The $\operatorname{Scotch}^{\mathrm{TM}}$ tape is bonded to a UHMWPE square $(1 \times 1 \mathrm{~cm})$ and peeled back at a $180^{\circ}$ angle and the process was repeated 10 times.

The abrasion test was adapted by $\mathrm{Lu}$ et $a .^{25} \mathrm{Cu}$-coated UHMWPE sample was placed face down on to the sandpaper with a standard weight of $100 \mathrm{~g}$ above. The two components were moved for a distance of $10 \mathrm{~cm}$ followed by $90^{\circ}$ rotations and the procedure repeated. Photographs were captured every 5 cycles for up to 10 cycles to keep track of the abrasion.

\section{Copper leaching assay}

The simulated body fluid (SBF) was prepared based on that described by Kokubo et al. ${ }^{26}$ A calibration curve was established by using various concentration of $\mathrm{Cu}$ precursor solution mentioned above. The Cu leaching from the sample was carried out by storing the sample in $25 \mathrm{~mL} \mathrm{SBF}$ at $37^{\circ} \mathrm{C}$ for $24 \mathrm{~h}$. The $\mathrm{Cu}$ concentration of the solution from the $\mathrm{Cu}$-coated UHWMPE to SBF was analysed by Microwave Plasma Atomic Emission Spectroscopy (4210 MP-AES, Agilent).

\section{Antimicrobial activity of Cu-coated UHMWPE}

Plate count method. Samples were tested against $S$. aureus $8325-4^{27}$ and $E$. coli ATCC 25922. Single bacterial colonies were 
inoculated in to brain heart infusion (BHI) broth $(10 \mathrm{~mL})$ and cultured aerobically at $37^{\circ} \mathrm{C}$ for $18 \mathrm{~h}$ with shaking at $200 \mathrm{rpm}$. The culture was collected by centrifugation $(4500 \times g)$ for $5 \mathrm{~min}$ and washed with phosphate-buffered saline (PBS) twice. The recovered culture was diluted 1000-fold in PBS to obtain an inoculum $\sim 10^{5} \mathrm{CFU} \mathrm{mL}{ }^{-1}$. Duplicates of each sample type were inoculated with $25 \mu \mathrm{L}$ of this inoculum. The samples were kept in the dark for $15 \mathrm{~min}$. After exposure each of the control sample was added to sterilised PBS $(450 \mu \mathrm{L})$ (neat suspension), vortexed to mix, and 10-fold serially diluted for plating, while the $\mathrm{Cu}$-coated UHMWPE samples were concentrated by centrifugation and re-suspended in $100 \mu \mathrm{L}$. E. coli was plated on MacConkey agar and mannitol salt agar was used for S. aureus. The plates were incubated aerobically at $37{ }^{\circ} \mathrm{C}$ for 24 hours (E. coli) and 48 hours (S. aureus). Each experiment was repeated three times.

\section{Antimicrobial test with the addition of BSA}

BSA was dissolved in PBS and sterilised by using a $0.2 \mathrm{~mm}$ syringe. The bacterial suspensions were diluted 1000-fold into the PBS solutions that contained $0.03 \%$ and $0.3 \%$ BSA. The modified bacterial suspensions were then exposed to the material as described above.

\section{Bacterial attachment assay}

LIVE/DEAD ${ }^{\mathrm{TM}}$ BacLight $^{\mathrm{TM}}$ Bacterial Viability Kit (Thermo Fisher Scientific) was applied to investigate bacterial attachment on to the sample surfaces. This test was done on the samples after removing the majority of the bacteria by vortexing, prior to staining. The dye solution was prepared according to the manufacturer's manual (Thermo Fisher Scientific). $250 \mu \mathrm{L}$ of the dye solution was directly added to the sample surface after exposure to the bacterial suspension and incubated for $10 \mathrm{~min}$ at room temperature in the dark before fluorescence imaging. A Leica DMIRB Inverted Fluorescence Microscope was adapted to capture fluorescence images with the aid of Q Capture software.

\section{Result and discussion}

UHMWPE has a high melt viscosity, such that consolidation can only be intrinsically achieved under elevated temperature and pressure. ${ }^{28}$ The UHMWPE substrate (Fig. 1(b)) with thickness of $c a .2 .34 \mathrm{~mm}$ was manufactured by adapting a lab scale compression moulding machine. Copper thin film was deposited on top of UHMWPE substrate via AACVD at $170{ }^{\circ} \mathrm{C}$ and demonstrated uniform coverage.

The copper precursor was synthesised from copper(II) formate tetrahydrate and 1-amino-propan2-ol in a modified procedure from previous literature. ${ }^{29,30}$ One advantage of using such a precursor is that the metal-organic decomposition (MOD) precursor has been proven to effectively address oxidation. ${ }^{31}$ In addition, the presence of a hydroxyl group in an amino alcohol can assist the copper metal salt to dissolve in a methanol solvent. ${ }^{32,33}$ The introduction of an amino alcohol can also act as a reducing agent, and therefore even though the copper salt has an intrinsic decomposition temperature of $200{ }^{\circ} \mathrm{C}$ (thermal analysis is shown in Fig. S4, ESI $\dagger$ ), the operation temperature can be maintained at $170{ }^{\circ} \mathrm{C}$ which is essential for a thermosensitive polymer. This is important as $170{ }^{\circ} \mathrm{C}$ is one of the lowest temperatures used in an AACVD processes. ${ }^{34}$ Normally a higher temperature is required to decompose the precursor and form a film. Hence by tailoring the precursor a temperature sensitive substrate can be effectively deposited. Thermal analysis of the precursor solution is available in Fig. S2 (ESI $\dagger$ ).

In general, a semicrystalline polymer tends to exhibit a flow transition state beyond its melting temperature. ${ }^{28}$ UHMWPE has a melting temperature $\left(T_{\mathrm{m}}\right)$ of $137{ }^{\circ} \mathrm{C} .{ }^{28}$ The survival of UHMWPE substrate above its $T_{\mathrm{m}}$ is due to the unique ultra-high density property that enables such a material to maintain its shape without experiencing other transition states. Thus, the deposition of $\mathrm{Cu}$ on UHMWPE substrate via AACVD is feasible since such material can withstand high temperature without changing state.

UHMWPE material has been used as acetabular component for over two decades. ${ }^{35}$ During an irradiation process, free radicals are formed due to the cleavage of the carbon-carbon bonds which encourage crosslinking predominantly occurs. ${ }^{36}$ However, minor residual free radicals formed from chain scission are trapped between crystalline lamellae. ${ }^{37}$ Crosslinking helps to restrict the mobility of the long polymeric chains and maintain the molecular structure, hence reduce the formation of the surface fibrils. ${ }^{35,38-40}$ Whereas residual free radicals interact with ambient oxygen and therefore cause breakdown of the polymeric structure. ${ }^{36}$ Thermal treatment such as remelting is therefore used to resolve oxidative deconstruction. ${ }^{36}$ This involves heating samples to above the $T_{\mathrm{m}}$ to eradicate free radicals, however this process has been reckoned to reduce the crystallinity and deteriorate the mechanical properties to the material. ${ }^{41}$ AACVD happens to have similar processed temperature as the remelting strategy, therefore DSC analysis and mechanical tests were carried out to investigate the effect of heat treatment on the mechanical properties of the UHMWPE substrate.

UHMWPE has mechanical properties which are correlated to its crystalline structure. Consequently, mechanical behaviour of the material is susceptible to any phase modification. ${ }^{42}$ This includes altering the crystallinity or crosslinking the amorphous region. ${ }^{42}$ DSC was performed to determine the percentage crystallinity before and after thermal treatment under an inert environment as per the ASTM F2625 - 10 standard. ${ }^{43}$ The sample was heated at a rate of $25 \mathrm{~K} \mathrm{~min}^{-1}$ from 25 to $170{ }^{\circ} \mathrm{C}$ which then maintained isothermally at $170{ }^{\circ} \mathrm{C}$ for $90 \mathrm{~min}$, cooled down at a rate of $25 \mathrm{~K} \mathrm{~min}^{-1}$ to $25{ }^{\circ} \mathrm{C}$ and subjected to another heating cycle up to $170{ }^{\circ} \mathrm{C}$ at $25 \mathrm{~K} \mathrm{~min}^{-1}$. The crystallinity of the samples was obtained by integrating the enthalpy peak from $50{ }^{\circ} \mathrm{C}$ to $160{ }^{\circ} \mathrm{C}$ which was then followed by normalisation with the heat of fusion of $100 \%$ crystalline polyethylene $\left(289.3 \mathrm{~J} \mathrm{~g}^{-1}\right)$. The percentage crystallinity of UHMWPE before remelting was determined from the first heat up step with a value of $69.0 \%$ (peak melting temperature $=137.7{ }^{\circ} \mathrm{C}$ ) whereas the sample after 
remelting was determined from the second heat up cycle with a value of $72 \%$ (peak melting temperature $=136.1{ }^{\circ} \mathrm{C}$ ).

The DSC analysis reveals whether the continuous high temperature AACVD process will have an adverse impact on the substrate of mechanical properties. The percentage crystallinity of the UHMWPE before and after remelting for $90 \mathrm{~min}$ had a minor fluctuation with around 3\% difference. Recent research has also investigated the effect of remelting UHMWPE above the melting temperature. ${ }^{36}$ Oral et al. has found that the heat treatment of unirradiated UHMWPE at $170{ }^{\circ} \mathrm{C}$ for $2 \mathrm{~h}$ did not affect the percentage of crystallinity. ${ }^{36}$ The percentage crystallinity remained constant at $63 \%$ with tolerance value of $2 \%$ and $1 \%$ respectively which was quite consistent with the calculated value above. ${ }^{36}$

A tensile testing machine was used to investigate the effect to the mechanical properties of UHMWPE after AACVD. Results (Table S1, ESI $\dagger$ ) illustrate that the high temperature treatment has no significant effect on the mechanical properties of the compression moulded UHMWPE substrate. The elongation at break before and after heat treatment was maintained at roughly $380 \%$. Even though the ultimate tensile strength and the stress at known strains (100\% and 300\% strain) have dropped slightly, the Young's modulus after remelting process has a change by less than $3.3 \%$.

XPS (Fig. 2) was used to identify the presence and chemical composition of the Cu-coated UHMWPE. Peaks were calibrated accordingly to carbon (1s) $(284.5 \mathrm{eV})$. Analysis revealed there was a mixture of copper in various oxidation states. $\mathrm{Cu} 2 \mathrm{p}_{3 / 2}$ has a binding energy at $932.9 \mathrm{eV}$ which deviates from the literature for $\mathrm{Cu}$ metal. ${ }^{44}$ This is due to the minor amount of $\mathrm{Cu}(\mathrm{I})$ present. ${ }^{44}$ Since the binding energy of $\mathrm{Cu}$ metal and $\mathrm{Cu}(\mathrm{I})$ is statistically similar, ${ }^{44}$ we assigned the main peak of $\mathrm{Cu} 2 \mathrm{p}_{3 / 2}$ consists as mixture of $\mathrm{Cu}(0)$ and $\mathrm{Cu}(\mathrm{I})$. Another fitted peak appears at $935.0 \mathrm{eV}$ which indicates the presence of $\mathrm{Cu}$ (II). This is also be corroborated by the presence of a minor shake-up satellite at $944.0 \mathrm{eV}$ (Fig. 2). ${ }^{44}$ Despite the fact that there is a mixture of $\mathrm{Cu}(\mathrm{I})$ and $\mathrm{Cu}(\mathrm{II})$ present, from the peak analysis we

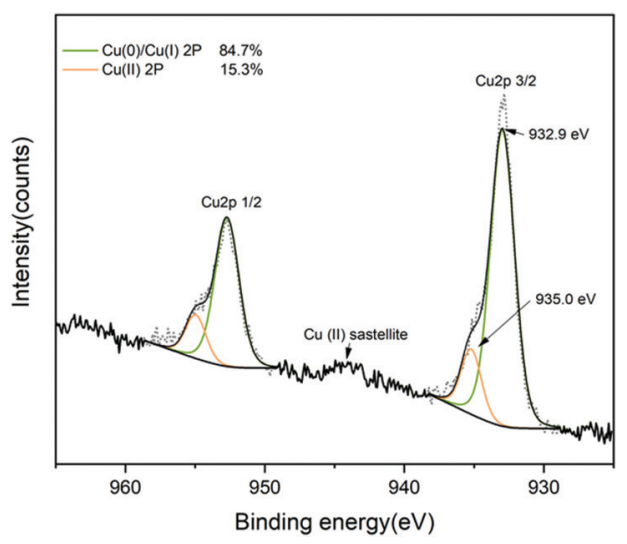

Fig. 2 XPS spectra of the surface of Cu-coated UHMWPE sample showing $\mathrm{Cu} 2 \mathrm{p}_{3 / 2}$ peak at $932.9 \mathrm{eV}$ matches to $\mathrm{Cu}(0)$ and $\mathrm{Cu}(\mathrm{I})$, an additional minor peak at $935.0 \mathrm{eV}$ and the shake-up satellite peak around $944 \mathrm{eV}$ correspond to $\mathrm{Cu}(\mathrm{II})$. find that among $85 \%$ of the $\mathrm{Cu}$ species are comprised $\mathrm{Cu}(0)$ and $\mathrm{Cu}(\mathrm{I})$ at the surface (top ten atomic layers).

The XPS depth profile for $\mathrm{Cu}(2 \mathrm{p})$ in Cu-coated UHMWPE was also obtained by using XPS with the aid of an argon source. The surface was etched for $300 \mathrm{~s}$. The satellite peaks in Fig. 2 due to $\mathrm{Cu}(\mathrm{II})$ have been reduced by the argon sputtering process, meanwhile the relative percentage composition of $\mathrm{Cu}(0) / \mathrm{Cu}(\mathrm{II})$ has also increased by approx. $10 \%$ as determined by the area under the fitted peaks. Fig. 3 shows that the $\mathrm{Cu} 2 \mathrm{p}_{3 / 2}$ peak has narrowed down with a slight shift to $932.5 \mathrm{eV}$ indicating a mixture of $\mathrm{Cu}(0)$ and $\mathrm{Cu}(\mathrm{I})$, which was consistent with the literature. ${ }^{45,46}$ It is known that during the etching process, oxygen can be preferentially reduced. ${ }^{47,48}$

The XRD analysis (Fig. 4) of the Cu-coated UHMWPE sample was carried out to obtain phase information. Two signature peaks at $22^{\circ}$ and $24^{\circ}$ correspond to the (110) and (200) plane of UHMWPE crystalline structure. ${ }^{49}$ Other diffraction peaks at $43^{\circ}$ and $51^{\circ}$ correspond to the (110) and (200) plane of $\mathrm{Cu}$ metal were seen. In addition, small peaks indicated by the two dashed lines in Fig. 4 are due to the trace amount of $\mathrm{Cu}_{2} \mathrm{O}$ present in the sample; consistent with the XPS result.

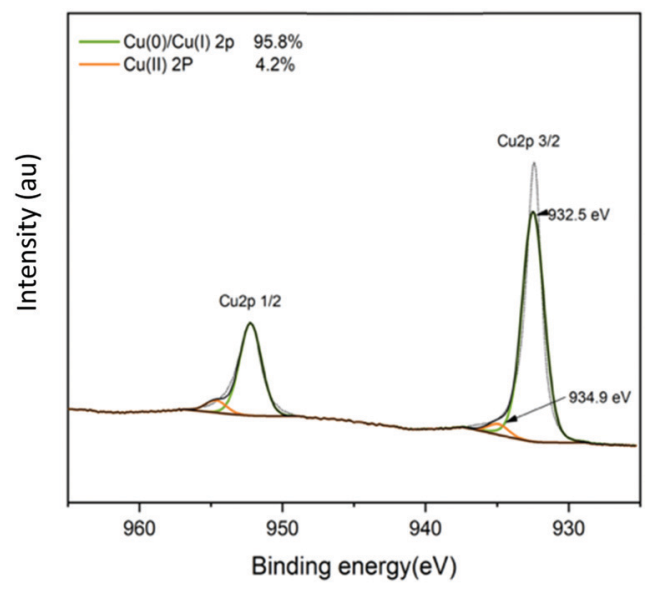

Fig. 3 Depth profile XPS of Cu-coated UHMWPE sample with Ar etch for 300 s showing the $\mathrm{Cu} 2 \mathrm{p}_{3 / 2}$ peak at $932.5 \mathrm{eV}$ matches to $\mathrm{Cu}(0)$ and $\mathrm{Cu}(1)$, an additional minor peak at $934.9 \mathrm{eV}$ corresponds to $\mathrm{Cu}\left({ }^{\prime \prime}\right)$.



Fig. 4 XRD patterns of Cu-coated UHMWPE sample with the ICSD standard shown in red. 
The average water contact angle for an uncoated UHMWPE sample is $99^{\circ}$ and for Cu-coated UHMWPE is $104^{\circ}$. UHMWPE powder is a naturally hydrophobic polymer. Deposition of $\mathrm{Cu}$ particles has strengthened the surface roughness and therefore Cu-coated UHMWPE demonstrates a slightly higher water contact angle. The morphology of the surface structure and $\mathrm{Cu}$ coating thickness are shown by the SEM images. Fig. 5(i and ii) show the low-resolution UHMWPE substrate prior and after the deposition of $\mathrm{Cu}$ coating. A microstructure of $\mathrm{Cu}$ cluster ranges from 100-300 $\mu \mathrm{m}$ closely packed but with pin holes in between has been clearly demonstrated in Fig. 5(ii). A closer look at the Cu-coated surface (Fig. 5(iii)) showed individual $\mathrm{Cu}$ nanoparticles. A cross-section view of the modified UHMWPE SEM image has also been captured to estimate the thickness of the $\mathrm{Cu}$ coating, Fig. 5(iv) reveals the average thickness is $10 \mu \mathrm{m}$.

The Cu-coated UHMWPE passed the Scotch ${ }^{\mathrm{TM}}$ tape adhesive test (Fig. 6) with no peeling or removal of the coating. Photos of the sample before and after the test are shown (Fig. 6, inset (i and ii)), no observable change can be seen post treatment. Microscopically, the $\mathrm{Cu}$ coating remained intact on the UHMWPE substrate which could be seen from the SEM images in Fig. 6(ii). This demonstrated that the $\mathrm{Cu}$ coating has good adhesion to the substrate. Sandpaper abrasion shows that the
Cu-coated UHMWPE sample, after 10 cycles, still retains the coating with only the edges becoming partially flattened (Fig. 7) due to the vigorous rubbing. The middle part of the sample (Fig. 7(ii) inset) showed virtually no damage. The surface integrity has been further confirmed by SEM as shown in Fig. 7(ii), indicating relatively low wear in the same area. Minor wear has been observed in Fig. 7(iii).

MP-AES is used to analyse the concentration of $\mathrm{Cu}$ leaching from Cu-coated UHMWPE into SBF. The $1 \times 1 \mathrm{~cm} \mathrm{Cu}$-coated UHMWPE was put into $25 \mathrm{~mL} \mathrm{SBF}$ at $37{ }^{\circ} \mathrm{C}$. Prior to MP-AES analysis, the eluted SBF was digested with aqua regia. The $\mathrm{Cu}^{2+}$ which has been leached out from the material surface was measured to have concentration of $1.64 \mathrm{ppm}$. This obtained result is quite encouraging as the tolerance amount of released $\mathrm{Cu}$ was considerably lower than the exposure limited stated by the Drinking Water Inspectorate UK $(20 \mathrm{ppm}) .{ }^{50}$

The MP-AES has detected minor amount of nascent $\mathrm{Cu}^{2+}$ from the Cu-coated UHWMPE. It is troublesome to distinguish the antimicrobial activity induced by the metal nanoparticles or its corresponding ions. ${ }^{51}$ Generally accepted antimicrobial $\mathrm{Cu}$ mechanism is the production of reactive oxygen species (ROS) via Fenton type reaction with subsequent cellular damage, ${ }^{52,53}$ but for its metal nanoparticle the antimicrobial properties can be due to their high surface-to-volume ratio and small
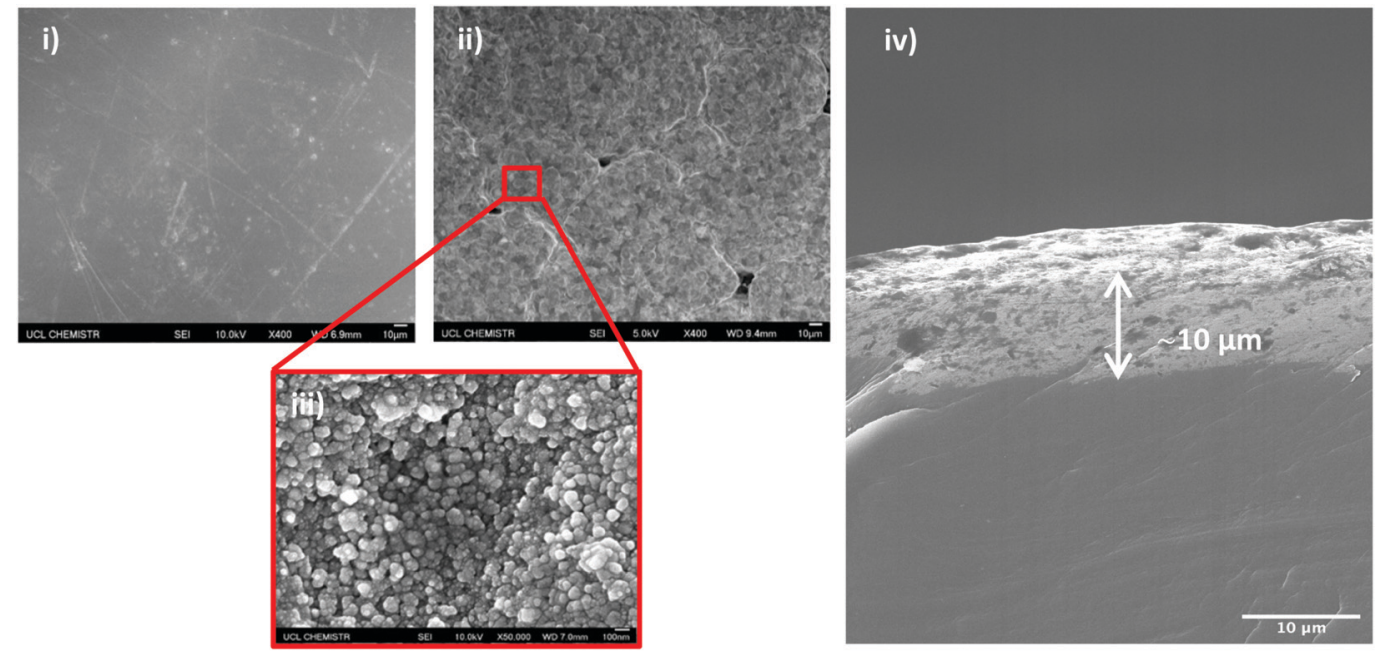

Fig. 5 SEM images of, (i) UHMWPE control, top down view with 400x magnification; (ii) Cu-coated UHMWPE, top down view with 400 $\times$ magnification; (iii) Cu-coated UHMWPE, top down view with $50000 \times$ magnification; (iv) cross-section view of the Cu coating on UHMWPE substrate.
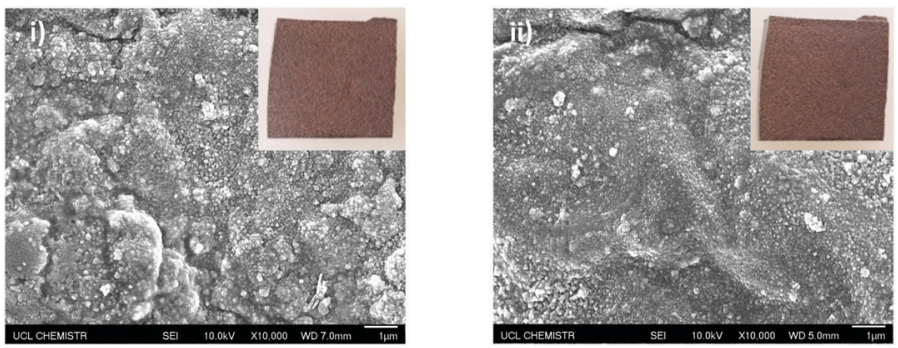

Fig. 6 SEM images of Cu-coated UHMWPE sample (i) prior and (ii) post to the Scotch ${ }^{\mathrm{TM}}$ tape adhesive test after ten cycles. Inset on top right of each SEM image is the photo of $\mathrm{Cu}$-coated UHMWPE sample prior and post to the $\mathrm{Scotch}^{\mathrm{TM}}$ tape adhesive test. 


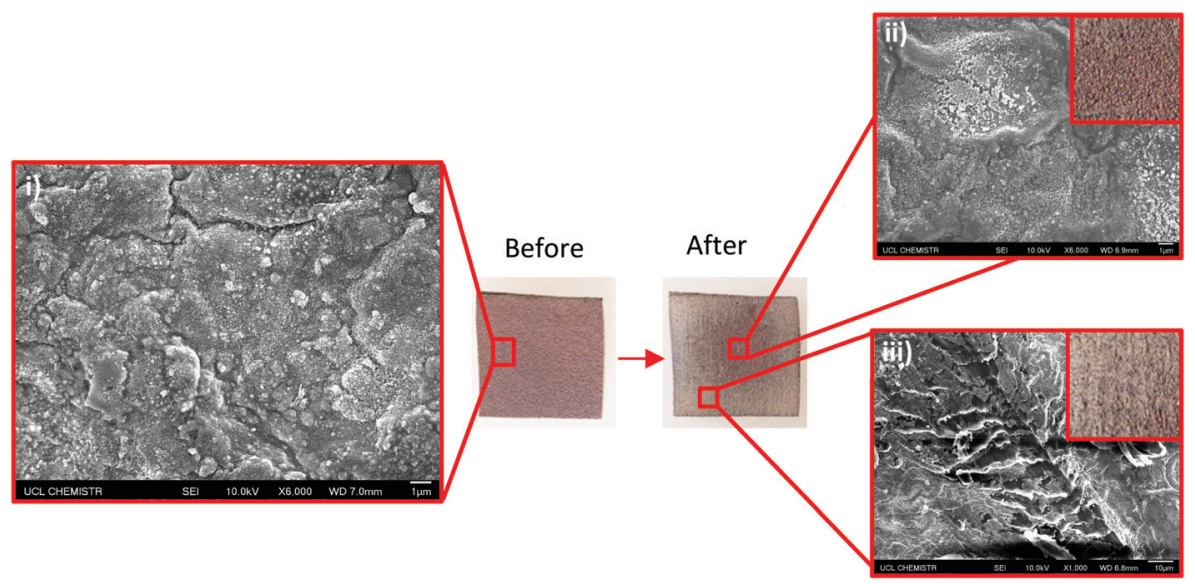

Fig. 7 Photos of CU-coated UHMWPE sample before and 10 cycles after the sandpaper abrasion test, (i) a SEM image of the Cu-coated UHMWPE surface prior to sandpaper abrasion test; (ii) and (iii) SEM images of the Cu-coated UHMWPE 10 cycles after the sandpaper abrasion test (inset top a zoom in diagram of the centre part; inset bottom: a zoom in diagram of the edge part).

sizes. ${ }^{10,54}$ This allows the antimicrobial agent to have close proximity to the bacterial cell and therefore initiate the fatal interaction. ${ }^{55}$ Chatterjee et al. unravel that the presence of $\mathrm{Cu}$ NP can trigger the cell filamentation by changing the cell membrane potential, namely polarisation. ${ }^{53}$ The work has also demonstrated that overproduction of ROS by Cu NP can trigger a significant amount of oxidation of unsaturated fatty acid in the cell membrane; modification of amino acid chain with subsequent structure change in proteins and DNA degradation, all these factors eventually lead to bacterial cell death. ${ }^{53}$

The antimicrobial efficacy of the Cu-coated UHMWPE was evaluated by testing against representative Gram-positive and Gram-negative bacteria, $S$. aureus and E. coli, respectively with added BSA at various concentrations (0\%, $0.03 \%$ and $0.3 \%)$. All antimicrobial tests were carried out in the dark to mimic an in vivo environment. Each sample was inoculated with $25 \mu \mathrm{L}$ of a bacterial suspension containing $\sim 10^{5}$ colony forming units (CFU) $\mathrm{mL}^{-1}$. A plate-count method was used to determine the number of surviving bacteria as previously described. ${ }^{56}$ The results (Fig. 8) show a pronounced bactericidal effect of the Cu-coated UHMWPE sample for all testing conditions (0\%, $0.03 \%$ and $0.3 \%)$. For both $S$. aureus and E. coli, in the absence of BSA, $c a .4 .55 \mathrm{log}$ and $4.81 \log$ reduction of the bacterial numbers, respectively was apparent within $15 \mathrm{~min}$ in the dark. The presence of BSA at either $0.03 \%$ or $0.3 \%$ did not reduce the bactericidal activity suggesting that the material is likely to remain active in an environment with organic soiling.

To confirm that the reduction in bacterial numbers recovered from the material was a consequence of bactericidal activity and not a result of increased adhesion to the test material, the materials were stained with live-dead stain after recovery of the bacteria in PBS. For both E. coli and S. aureus, similar trace amounts of bacteria were left attached to both the test and control materials. These tests showed that the bacteria left on the copper coated sample were stained red and hence dead whereas those on the control sample were alive. Fluorescence images are shown in Fig. S5 (ESI†).

Copper containing ceramic materials have been studied previously for antimicrobial activity. ${ }^{10,34,57}$ Alotaibi developed a $\mathrm{Cu}-\mathrm{ZrO}_{2}$ composite via high temperature $\left(430{ }^{\circ} \mathrm{C}\right) \mathrm{AACVD}$ to
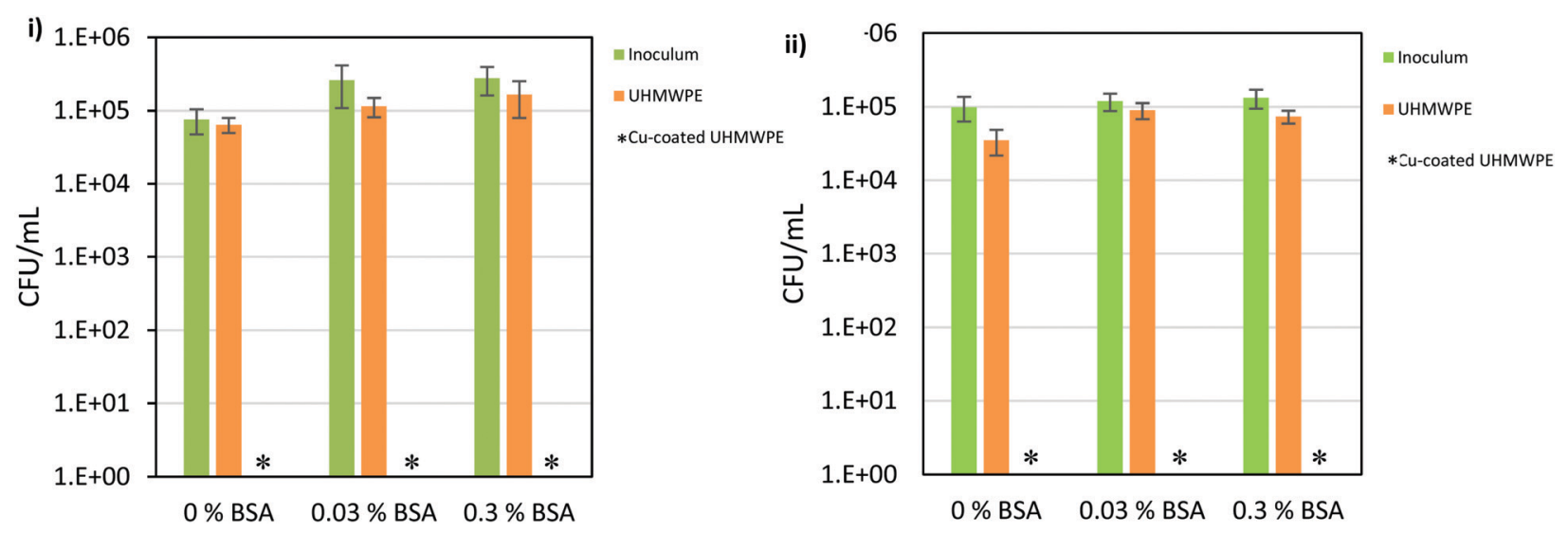

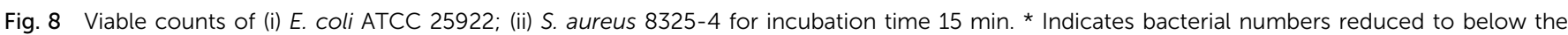
detection limit of 1 bacterium. 
achieve a $4.5 \log _{10}$ reduction in the numbers of $E$. coli in the dark after only $20 \mathrm{~min}$. For $S$. aureus, the number fell below the detection limit of $100 \mathrm{CFU} \mathrm{mL}{ }^{-1}$ after $60 \mathrm{~min}^{34}$ Other research, conducted by Sehmi et al., showed that copper nanoparticles could be embedded into polyurethane through a swellencapsulation shrink method. ${ }^{10}$ When tested against an epidemic methicillin-resistant $S$. aureus strain, ${ }^{10} \mathrm{Cu}$-polyurethane demonstrated $\geq 4 \log _{10}$ reduction of bacterial number in $2 \mathrm{~h}$ in the dark. Whereas for E. coli, a similar reduction took $3 \mathrm{~h}^{10}$ In this study, the Cu-coated UHMWPE has copper in the form of the metal and copper(II) and/or copper(I) oxide. Previous research has shown that copper oxide exhibits antimicrobial activity with a $4.7 \log _{10}$ reduction in $S$. aureus numbers after $1 \mathrm{~h}$ and a $2.7 \log _{10}$ reduction for $E$. coli in the same time period. ${ }^{57}$ Previous work from our laboratory evaluating antimicrobial polymers has shown that Gram-positive bacteria are usually susceptible than Gram-negative bacteria. In contrast, the material reported here shows comparable bactericidal activity against $E$. coli and $S$. aureus. The potent antimicrobial property of the Cu-coated UHMWPE showed the highest net bacterial reduction for the shortest time period.

\section{Conclusion}

This is, to the best of our knowledge, the first time that an antimicrobial coating has been achieved on UHMWPE through low-temperature AACVD. The remarkable antibacterial property manifests without the activation of any light source. With only 15 min exposure time, the material demonstrated an average $5 \log _{10}$ reduction in the numbers of both Gram-positive and Gram-negative bacteria (equivalent to $99.999 \%$ kill efficiency). The conditions needed to make these films required a precursor that would decompose at the softening point of the polymer $\left(170{ }^{\circ} \mathrm{C}\right.$ chosen). Surprisingly this led to a strong interaction between the polymer and enabled the copper film to anchor and bind effectively to the polymer surface. It is this combination that enabled the coating to be rugged and resistant to harsh abrasion (sand paper) and tape peeling.

This novel and highly competent antimicrobial material is a potential candidate for application to prosthetic joints. With such promising antimicrobial results, cytocompatibility needs to be carried out in forthcoming studies and regulations for the clinical application of copper containing materials should be prioritised in the future work.

\section{Conflicts of interest}

All authors have no conflicts of interest to declare.

\section{Acknowledgements}

S. P. Douglas thanks the EPSRC for their financial support. C. E. K. acknowledges EPSRC grant EP/N509577/1. K. Wu and E. Allan thank Dr Nicky Morden for her technical assistance. $\mathrm{K}$. Wu thanks Mr Cláudio Laurenço for his advice on microbiology and thanks Dr Fabiola Sciscione, Ms Katerina McCann, Ms Evelin Karageorgiou and Ms Heike Lee-Muller for equipment training.

\section{References}

1 National Joint Registry for England, Wales, Northern Ireland and the Isle of Man 15th Annual Report [Internet], 2018, available from: http://www.njrreports.org.uk.

2 J. W. Kuiper, R. T. Willink, D. J. Moojen, M. P. Bekerom and S. Colen, World J. Orthop., 2014, 5(5), 667-676.

3 National Joint Registry for England, Wales, Northern Ireland and the Isle of Man 14th Annual Report, National Joint Registry, 2017, available from: http://www.njrreports.org.uk.

4 W. Zimmerli, A. Trampuz and P. E. Ochsner, N. Engl. J. Med., 2004, 351(16), 1645-1654.

5 A. J. Tande and R. Patel, Clin. Microbiol. Rev., 2014, 27, 302-345.

6 V. J. Suhardi, D. A. Bichara, S. J. J. Kwok, A. A. Freiberg, H. Rubash, H. Malchau, S. H. Yun, O. K. Muratoglu and E. Oral, Nat. Biomed. Eng., 2017, 1(6), 80.

7 E. M. Hetrick and M. H. Schoenfisch, Chem. Soc. Rev., 2006, 35(9), 780-789.

8 R. E. Barth, H. Charles Vogely, A. I. M. Hoepelman and E. J. G. Peters, Int. J. Antimicrob. Agents, 2011, 38, 371-375.

9 J. A. P. Geurts, D. M. C. Janssen, A. G. H. Kessels and G. H. I. M. Walenkamp, Acta Orthop., 2013, 84, 509-516.

10 S. K. Sehmi, S. Noimark, J. Weiner, E. Allan, A. J. Macrobert and I. P. Parkin, ACS Appl. Mater. Interfaces, 2015, 22807-22813.

11 Y. Z. Wan, S. Raman, F. He and Y. Huang, Vacuum, 2007, 81, 1114-1118.

12 K. Peters, M. Pazos, Z. Edoo, J.-E. Hugonnet, A. M. Martorana, A. Polissi, M. S. Vannieuwenhze, M. Arthur and W. Vollmer, Proc. Natl. Acad. Sci. U. S. A., 2018, 115(42), 10786-10791.

13 G. Grass, C. Rensing and M. Solioz, Appl. Environ. Microbiol., 2011, 77(5), 1541-1547.

14 C. E. Knapp, E. A. Metcalf, S. Mrig, C. Sanchez-Perez, S. P. Douglas, P. Choquet and N. D. Boscher, ChemistryOpen, 2018, 7, 850-857.

15 C. E. Knapp, J.-B. Chemin, S. P. Douglas, D. A. Ondo, J. Guillot, P. Choquet and N. D. Boscher, Adv. Mater. Technol., 2018, 3, 1700326.

16 J. S. Chen, Z. Sun, P. S. Guo, Z. B. Zhang, D. Z. Zhu and H. J. Xu, J. Appl. Phys., 2003, 93, 5103-5108.

17 B. C. Anderson, P. D. Bloom, K. G. Baikerikar, V. V. Sheares and S. K. Mallapragada, Biomaterials, 2002, 23(8), 1761-1768.

18 C. A. Flemming and J. T. Trevors, Water, Air, Soil Pollut., 1989, 44, 143-158.

19 X. Gao, M. Hua, J. Li and W. Gao, Hip Jt. Mater. J. Dispers. Sci. Technol., 2009, 30, 1059-1066.

20 L. Wu, X. Gao, D. Wang, J. Li, W. Gao and M. Hua, J. Dispersion Sci. Technol., 2011, 32, 680-685.

21 M. Azizi, H. Ghourchian, F. Yazdian, F. Dashtestani and H. AlizadehZeinabad, PLoS One, 2017, 12, e0188639.

22 Intrauterine device (IUD) - NHS [Internet], available from: https://www.nhs.uk/conditions/contraception/iud-coil/. 
23 C. Audio Lourenço, T. J. Macdonald, A. Gavriilidis, E. Allan, A. J. Macrobert and I. P. Parkin, $R S C A d v .$, 2018, 8, 34252-34258.

24 ASTM D638-14, Standard Test Method for Tensile Properties of Plastics, ASTM International, 2016.

25 Y. Lu, S. Sathasivam, J. Song, C. R. Crick, C. J. Carmalt and I. P. Parkin, Science, 2015, 347(5226), 1132-1135.

26 T. Kokubo and H. Takadama, Biomaterials, 2006, 27, 2907-2915.

27 S. Herbert, A.-K. Ziebandt, K. Ohlsen, T. Schäfer, M. Hecker, D. Albrecht, R. Novick and F. Götz, Infect. Immun., 2010, 78, 2877-2889.

28 S. M. Kurtz, in UHMWPE Biomaterials Handbook, ed. S. M. Kurtz, Elsevier, 3rd edn, 2016, pp. 7-20.

29 Y. Farraj, M. Grouchko and S. Magdassi, Chem. Commun., 2015, 51, 1587-1590.

30 Y. Farraj, A. Smooha, A. Kamyshny and S. Magdassi, ACS Appl. Mater. Interfaces, 2017, 9, 8766-8773.

31 A. Yabuki, N. Arriffin and M. Yanase, Thin Solid Films, 2011, 519(19), 6530-6533.

32 S. S. Magdassi, Y. Farraj, M. Grouchko and S. Magdassi, Chem. Commun., 2015, 51, 1587-1590.

33 D.-H. Shin, S. Woo, H. Yem, M. Cha, S. Cho, M. Kang, S. Jeong, Y. Kim, K. Kang and Y. Piao, ACS Appl. Mater. Interfaces, 2014, 6, 3312-3319.

34 A. M. Alotaibi, S. Sathasivam, S. P. Nair and I. P. Parkin, J. Mater. Chem. B, 2016, 4, 666-671.

35 O. K. Muratoglu and C. R. Bragdon, in UHMWPE Biomaterials Handbook, ed. S. M. Kurtz, Elsevier, 3rd edn, 2016, pp. 197-203.

36 E. Oral, A. S. Malhi and O. K. Muratoglu, Biomaterials, 2006, 27, 917-925.

37 S. K. Bhateja, R. W. Duerst, E. B. Aus and E. H. Andrews, J. Macromol. Sci., Part B: Phys., 1995, 34, 263-272.

38 A. Wang, D. C. Sun, S.-S. Yau, B. Edwards, M. Sokol, A. Essner, V. K. Polineni, C. Stark and J. H. Dumbleton, Wear, 1997, 203-204, 230-241.

39 P. Bracco, A. Bellare, A. Bistolfi, S. Affatato, P. Bracco, A. Bellare, A. Bistolfi and S. Affatato, Materials, 2017, 10, 791.
40 H. McKellop, F. Shen, B. Lu, P. Campbell and R. Salovey, J. Orthop. Res., 1999, 17, 157-167.

41 S. M. Kurtz and J. D. Patel, in UHMWPE Biomaterials Handbook, ed. S. M. Kurtz, Elsevier, 3rd edn, 2016, pp. 57-71.

42 M. C. Sobieraj and C. M. Rimnac, J. Mech. Behav. Biomed. Mater., 2009, 2, 433-443.

43 ASTM F2625 - 10, Standard Test Method for Measurement of Enthalpy of Fusion, Percent Crystallinity, and Melting Point of Ultra-High-Molecular Weight Polyethylene by Means of Differential Scanning Calorimetry, 2016.

44 M. C. Biesinger, Surf. Interface Anal., 2017, 49, 1325-1334.

45 J. C. Fuggle, E. Källne, L. M. Watson and D. J. Fabian, Phys. Rev. B: Condens. Matter Mater. Phys., 1977, 16, 750-761.

46 G. Deroubaix and P. Marcus, Surf. Interface Anal., 1992, 18, 39-46.

47 G. Deng, N. Xanthopoulos and P. Muralt, Appl. Phys. Lett., 2008, 92, 172909.

48 H. Bubert, E. Grallath, A. Quentmeier, M. Wielunski and L. Borucki, Fresenius' J. Anal. Chem., 1995, 353, 456-463.

49 D. S. Xiong, J. M. Lin and D. L. Fan, Biomed. Mater., 2006, 1, 175-179.

50 Drinking Water Inspectorate, available from: http://dwi. defra.gov.uk/private-water-supply/local-auth/parameters.html.

51 J. P. Ruparelia, A. K. Chatterjee, S. P. Duttagupta and S. Mukherji, Acta Biomater., 2008, 4(3), 707-716.

52 A. M. Alotaibi, S. Sathasivam, S. P. Nair and I. P. Parkin, J. Mater. Chem. B, 2016, 4(4), 666-671.

53 A. K. Chatterjee, R. Chakraborty and T. Basu, Nanotechnology, 2014, 25, 135101.

54 E. Ozkan, C. C. Crick, A. Taylor, E. Allan and I. P. Parkin, Chem. Sci., 2016, 7(8), 5126-5131.

55 J. Ramyadevi, K. Jeyasubramanian, A. Marikani, G. Rajakumar and A. A. Rahuman, Mater. Lett., 2012, 71, 114-116.

56 S. Noimark, C. W. Dunnill, C. W. M. Kay, S. Perni, P. Prokopovich, S. Ismail, M. Wilson and I. P. Parkin, J. Mater. Chem., 2012, 22, 15388.

57 I. A. Hassan, I. P. Parkin, S. P. Nair and C. J. Carmalt, J. Mater. Chem. B, 2014, 2, 2855-2860. 